\title{
Ileo-perineal fistula: Rare late complication after rectal amputation - clinical case
}

\author{
Fistulă ileo-perineală: Complicaţie tardivă rară după \\ amputaţia de rect - caz clinic
}

\author{
Andrei Iulian Toader ${ }^{1,2}$, Călin Pavel Cobelschii ${ }^{1,2}$, Aurel Mironescu ${ }^{1,3}$, \\ Alfred Redalf Alain Gheorghiu', ${ }^{1,2}$, Adrian Maier ${ }^{2}$, Andreea Mădălina Toader ${ }^{2}$ \\ ${ }^{1}$ Facultatea de Medicină, Universitatea Transilvania, Brașov, România \\ ${ }^{2}$ Spitalul Clinic Judeţean de Urgenţă, Brașov, România \\ ${ }^{3}$ Spitalul Clinic de Copii, Brașov, România
}

\begin{abstract}
Abdominal-perineal rectal amputation retains a well-defined place in the surgical treatment of rectal cancer, despite technical advances. The authors present the case of a 67-year-old patient who developed an entero-perineal fistula involving the last ileal loop, two years after an abdominal-perineal rectal amputation for a radiotreated rectal neoplasm. For surgical treatment of the fistula, right ileo-hemicolectomy with ileo-transverse anastomosis were performed. The fistulous tract is treated by soft field typhoon meshing in the same manner of treating the perineal wound after rectal amputation. The evolution is favorable, with the closure of the perineal wound, 6 weeks after surgery. The peculiarity of the case consists in the way of surgical solution. This case presentation is important due to the rarity of the ileo-perineal fistula after amputation of the rectum, as well as due to the particular way of surgical resolution.
\end{abstract}

Keywords: rectal amputation, perineal fistula

\section{REZUMAT}

Amputaţia de rect pe cale abdomino-perineală își păstrează un loc bine definit în tratamentul chirurgical al cancerului de rect, în ciuda progreselor tehnice. Autorii prezintă cazul unui pacient, în vârstă de 67 de ani, care a dezvoltat o fistulă entero-perineală interesând ultima ansă ileală, la doi ani după o amputaţie de rect efectuată pe cale abdomino-perineală, pentru un neoplasm rectal radiotratat. Pentru tratamentul chirurgical al fistulei, se practică ileo-hemicolectomie dreaptă cu ileo-transverso-anastomoză. Traiectul fistulos este tratat prin meșaj cu câmpuri moi într-o manieră similară tratării plăgii perineale după amputaţia de rect. Evoluţia este favorabilă, cu închiderea plăgii perineale la 6 săptămâni de la operaţie. Particularitatea cazului constă în modul de rezolvare chirurgicală. Prezentarea cazului este importantă datorită rarităţii fistulei ileo-perineale după amputaţia de rect, precum și datorită modalităţii particulare de rezolvare chirugicală.

Cuvinte cheie: amputaţie de rect, fistulă perineală

\section{INTRODUCERE}

Cancerul colorectal este o suferinţă frecventă în lume, responsabilă de un număr crescut de decese, iar managementul terapeutic multidisciplinar include chimioterapia, radioterapia, precum și chirurgia (1).

Concepută în anii 1930 de către Ernest Miles, amputaţia de rect pe cale abdomino-perineală, la ora actuală, este indicată la pacienţii cu invazie tumorală a sfincterului, cu disfuncţie sau incontinen- ţă sfincteriană primară, cu tumori voluminoase sau slab diferenţiate ale rectului inferior, precum și în cazurile în care prezervarea aparatului sfincterian împiedică o rezecţie în limite de siguranţă oncologică (2).

În ciuda progreselor din ultimii ani (chirurgie laparoscopică, chirurgie robotică, chirurgie endoanală etc.), amputaţia de rect pe cale abdomino-perineală își păstrează un rol important în arsenalul terapeutic chirugical al cancerului de rect (2). 
Fistula entero-perineală este o complicaţie de excepţie a acestei intervenţii chirurgicale și este legată în principal de spaţiul „mort“ postoperator pelvin. La ora actuală, există multiple procedee chirurgicale de rezolvare a acestui spaţiu (sutura primară, utilizarea de lambouri musculare, omentoplastie, meșe sintetice), la care se adaugă testarea unor tehnici noi (utilizare de polimeri, de materiale compozite, de monofibre biodegradabile) (3).

Modalităţile multiple de desfiinţare a acestui spaţiu creează dificultăţi în alegerea unui procedeu simplu şi eficient. Noi propunem utilizarea meșajului plăgii perineale cu câmpuri moi, care sunt suprimate la 4-5 zile postoperator. Metoda este simplă, iar rezultatele sunt bune (4).

Fistula entero-perineală este bine definită clinic și este o suferinţă care provoacă alterarea calităţii vieţii pacientului (asemănător incontinenţei sfincteriene), fapt ce impune efectuarea de studii suplimentare cu elucidarea epidemiologiei, a etiopatogeniei, precum și a unei terapii eficiente.

\section{PREZENTAREA CAZULUI}

Datele au fost culese din FOCG a pacientului, din protocolul operator, precum și din buletinul histopatologic. Menţionăm faptul că toate intervenţiile chirurgicale și internările au avut loc în același serviciu chirugical.

Prezentăm cazul unui pacient, P.C., în vârstă de 67 de ani, cu dislipidemie, care s-a internat în serviciul nostru (FOCG 19415 din 11.11.2020) pentru dureri perineale și evacuare de material intestinal printr-un orificiu fistulos al plăgii perineale postoperatorii, simptome cu o durată de aproximativ 3 săptămâni înaintea internării. Menţionăm că volumul conţinutului intestinal exteriorizat la nivel perineal necesită schimbarea pansamentului și a lenjeriei de 5-6 ori pe zi, fapt ce alterează calitatea vieţii pacientului.

Din antecedentele personale patologice, menţionăm că, pe 28.11.2018, pacientul a suferit o amputaţie de rect pe cale abdomino-perineală cu anus iliac stâng maturat primar, pentru un adenocarcinom de rect inferior $(4 \mathrm{~cm}$ de la orificiul anal extern), radiotratat (radioterapie neoadjuvantă).

Pe 08.04.2019, la 5 luni după amputaţia de rect, pacientul se internează pentru un sindrom subocluziv care răspunde favorabil tratamentului medical: antisecretorii, prokinetice, antialgice, reechilibrare hidro-electrolitică și volemică. De menţionat că examinarea endoscopică a tubului digestiv (endoscopie superioară și inferioară), precum și examinarea tomografică (CT torace și abdomen) nu decelează recidivă tumorală sau boală metastatică.
Pe 15.07.2019, la 8 luni de la amputaţia de rect, pacientul se reinternează pentru tabloul clinic și imagistic al unei ocluzii intestinale. Se intervine chirugical de urgenţă şi se evidenţiază aderenţe peritoneale viscero-viscerale interesând ileonul și peritoneul pelvin. Se practică disecţia laborioasă a aderenţelor, cu eliberarea anselor intestinale, exceptând ultima ansă ileală imposibil de disecat și de mobilizat din excavaţia pelvină, motiv pentru care se optează pentru șuntarea obstacolului, efectuând o ileo-transverso-anastomoză latero-laterală. Evoluţia postoperatorie a fost favorabilă.

În cursul internării actuale, la examenul clinic se decelează un orificiu fistulos la nivelul plăgii perineale postoperatorii (după amputaţia de rect pe cale abdomino-perineală) prin care se exteriorizează material intestinal (Fig. 1). Examinările biologice decelează o anemie ușoară $(\mathrm{Hb}=11,4 \mathrm{~g} / \mathrm{dl}, \mathrm{Ht}=36 \%)$, iar testul PCR de detectare a SARS-CoV-2 este negativ. Markerii tumorali sunt, de asemenea, negativi. Examinarea tomografică a abdomenului și pelvisului, cu substanţă de contrast decelează o colecţie presacrată fistulizată perineal, interfesier. După o pregătire preoperatorie corespunzătoare, cu diagnosticul de fistulă entero-perineală, se intervine chirurgical în AG cu IOT prin abord median larg. Intraoperator, se constată aderenţe peritoneale viscero-viscerale și viscero-parietale, care se lizează. Cecul, apendicele cecal și ultima ansă ileală sunt „căzute“ în cavitatea pelvină restantă după amputaţia de rect şi comportă cu pelvisul aderenţe foarte strânse, „lemnoase“. Se observă și o stenoză de anastomoză ileo-transversă (lumen sub $2 \mathrm{~cm}$ ). Disecţia laborioasă a aderenţelor entero-pelvine evidenţiază o fistulă ileo-perineală, orificiul ileal al fistulei fiind situat la 7-8 cm de valva ileo-cecală. Se practică ileo-hemicolectomie dreaptă (Fig. 2), cu respectarea anastomozei ileo-colice stenozate și efectuarea unei alte anastomoze ileo-transverse, mai largă, în aval de prima. Controlul hemostazei, toaleta, drenajul peritoneal și parietorafia anatomică încheie intervenţia chirurgicală. Traiectul fistulos perineal, care se deschide la nivelul plăgii perineale, este lavat abundent cu soluţii antiseptice și meșat cu câmp moale. Meșa s-a suprimat a 5-a zi postoperator. Evoluţia postoperatorie a fost favorabilă sub tratament antibiotic cu spectru larg, antialgic, antisecretor, de reechilibrare hidro-electrolitică și volemică cu HMMM, local. Mobilizarea precoce este urmată de reluarea tranzitului intestinal pentru materii fecale și gaze, a alimentaţiei și a hidratării per os, fapt ce a permis externarea pacientului în a 7-a zi postoperator, cu plaga în curs de vindecare. 


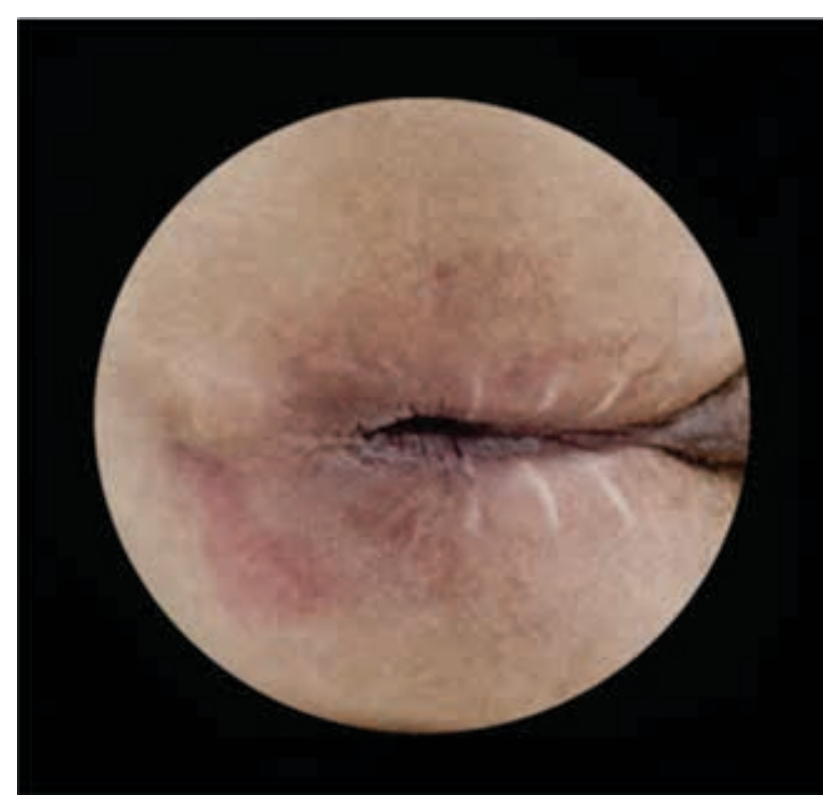

FIGURA 1. Orificiu fistulos la nivelul plăgii perineale postoperatorii

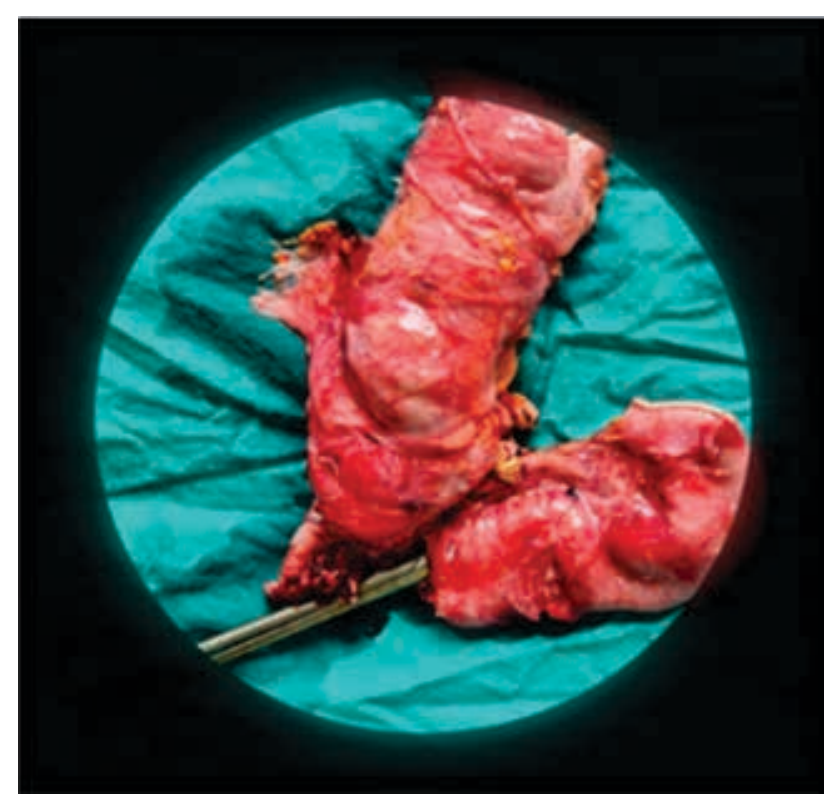

FIGURA 2. Piesa de ileo-hemicolectomie dreaptă cu orificiul fistulos (indicat cu un foarfece)

Postoperator, se constată o scădere semnificativă a volumului de lichid exteriorizat prin orificiul extern al fistulei perineale, fapt ce necesită 1-2 pansamente pe zi. De data aceasta, lichidul este sero-hematic.

Controlul bisăptămânal în ambulatoriul de specialitate identifică închiderea fistulei perineale la 6 săptămâni de la intervenţia chirurgicală.

Menţionăm că piesa de ileo-hemicolectomie a fost analizată în serviciul de anatomie patologică al Spitalului Clinic Judeţean de Urgenţă Braşov, iar examenul microscopic relevă perete de intestin subţire cu traiect fistulos delimitat de ţesut de granulaţie, vase de neoformaţie şi intens infiltrat inflamator cronic limfo-plasmocitar. Nu se constată elemente de malignitate și nici modificări de enterită radică.

\section{DISCUȚII}

Deoarece tehnica amputaţiei de rect nu include nicio anastomoză, fistula digestivă nu este o complicaţie postoperatorie comună. În apariţia acestei complicaţii, sunt incriminaţi următorii factori: vârsta, tarele asociate ale pacientului, radioterapia și chimioterapia $(5,6)$.

În cursul amputaţiei de rect pe cale abdominoperineală, se extirpă rectul, mezorectul, complexul sfincterian și o parte din mușchii ridicători anali, rezultând un cilindru cu o lungime de $10-20 \mathrm{~cm}$ și un diametru de $6-8 \mathrm{~cm}$. Acest spaţiu „mort“ pelvin nu poate fi redus din cauza lipsei de elasticitate a pelvisului osos. Cea mai comună complicaţie a spaţiului „mort“" pelvin este angajarea unei anse de intestin subţire cu apariţia herniei perineale, cu risc crescut de strangulare și fistulă enterală $(3,7,8)$.

Hernia perineală după rezecţia de rect deschisă a fost raportată prima dată în 1939 de Yeomans, iar după amputaţia de rect laparoscopică, în 2007, de Veenhof (7).

Pentru desfiinţarea acestui spaţiu „mort" şi evitarea complicaţiilor legate de acesta, actualmente, există o serie de proceduri chirurgicale utilizate, după cum urmează: sutură primară, utilizarea de lambouri musculare (ridicători anali, gracilis, gluteus), omentoplastie, utilizarea de materiale sintetice şi biologice $(3,6)$.

Multitudinea procedeelor amintite trădează faptul că niciuna dintre ele nu s-a impus ca metodă de elecţie. O alternativă demnă de menţionat datorită simplităţii și a rezultatelor bune este meșajul cu câmpuri moi al spaţiului „mort“ pelvin după amputaţia de rect și suprimarea meșelor a 4-a sau a 5-a zi postoperator (4). Această tehnică face ca aderenţele viscero-viscerale postoperatorii să menţină ansele intestinale deasupra pelvisului. Evoluţia pacientului prezentat, $\mathrm{cu}$ angajarea ultimei anse ileale în pelvis, demonstrează că nici acest procedeu nu este lipsit de riscuri.

Radioterapia neoadjuvantă este un factor de risc pentru fixarea intestinului subţire în pelvis. Pentru diminuarea acestui risc, se preferă ședinţele scurte de radioterapie (9).

Enterita radică crește riscul de fistule postoperatorii, dar prezintă modificări microscopice caracteristice de vasculită ocluzivă (depunere de colagen, apariţia celulelor spumoase în intimă, depuneri de material hialin (10), elemente care nu se regăsesc pe piesa examinată. 
Ultima ansă ileală probabil că s-a ,așezat“ în cavitatea pelvină (spaţiul ,,mort") imediat postoperator. Aderenţele au apărut și s-au consolidat cu timpul, devenind foarte strânse, ,lemnoase“. În condiţiile ocluziei intestinale, la 8 luni de la amputaţia de rect, am considerat mai puţin lipsită de riscuri realizarea unei anastomoze ileo-transverse decât disecţia cu orice preţ a ansei ileale cu probabilitatea efracţiei acesteia și contaminarea cavităţii peritoneale. Lăsat „pe loc“ în cursul intervenţiei pentru ocluzie intestinală, complexul aderenţial ileo-pelvin evoluează spre fistulă ileo-perineală. Prezenţa fistulei, prin șuntarea conţinutului intestinal, probabil că a favorizat stenoza gurii de anastomoză ileo-transversă.

În concordanță cu alte cazuri din literatură $(5,7)$, şi în cazul nostru apariţia fistulei digestive postoperatorii s-a corelat cu vârsta înaintată, cu tehnica chirugicală (amputaţia de rect cu crearea spaţiului mort pelvin) şi cu radioterapia neoadjuvantă. Principiul terapeutic chirugical este de rezecţie a segmentului intestinal cu orificiul fistulos şi refacerea continuităţii digestive prin anastomoză (5), principiu respectat și de noi.

Anastomoza ileo-transversă, ca modalitate de rezolvare a ocluziei intestinale prin aderenţă ileopelvină, nu a ferit pacientul de apariţia fistulei, dar a permis rezolvarea acesteia în condiţii elective, programate și, implicit, cu diminuarea riscului de complicaţii postoperatorii.

Similar modalităţii de rezolvare a spaţiului mort pelvin după amputaţia de rect, am utilizat meșajul traiectului fistulos, cu rezultate bune la două luni de la operaţie.

O altă particularitate o reprezintă faptul că pacientul prezentat a fost tratat, îngrijit și supravegheat

Conflict of interest: none declared

Financial support: none declared

\section{BIBLIOGRAFIE}

1. Oldani A, Cesana G, Uccelli M, Ciccarese F, Giorgi R, M De Carli S, Villa R, Olmi S. Surgical Outcomes of Rectal Resection: Our 10 Years Experience.J Laparoendosc Adv Surg Tech A. 2019 Jun;29(6):820-825.

2. Feig BW, Ching CD. The MD Anderson Surgical Oncology Hand Book. Fifth Edition. Philadelphia. Ed. Lippincott Williams \& Wilkins. 2012:378-379.

3. Bockova M, Hoch J, Kestlerova A, Amler E. The Dead Space After Extirpation of Rectum. Current Management and Searching for New Materials for Filling. Physiol Res. 2019;68:509-515.

4. Toader I, Cobelschi C, Mironescu A, Hogea D, Gheorghiu A, Maier A. Management of Perineal Wound Post Rectal Amputation. Bulletin of the Transilvania University of Braşov Series VI: Medical Sciences. 2017;10:13-18.

5. Coman IS, Coman EV, Florea CG, David OI et al. Recidivă locală și fistule digestive succesive după amputaţie de rect la un pacient cu boală polichistică hepato-renală în fază avansată - Prezentare de caz. Chirurgia. 2020;115:155. postoperator de către aceeași echipă chirurgicală, fapt ce a facilitat înţelegerea cazului, cât și comunicarea cu pacientul și complianţa la tratament.

Importanţa prezentării cazului constă în frecvenţa rară a acestei patologii și a modalităţii de rezolvare chirurgicală. Tratamentul fistulei enteroperineale după amputaţia de rect are ca obiective îndepărtarea orificiului fistulos enteral prin enterectomie, desfiinţarea traiectului fistulos și restabilirea continuităţii digestive. Individualizarea tratamentului, adaptat fiecărui caz, este dată de localizarea și extensia rezecţiei, precum și de modalitatea de rezolvare a traiectului fistulos (în cazul nostru, ileo-hemicolectomie dreaptă cu ileo-transverso-anastomoză și meșajul traiectului fistulos).

\section{CONCLUZII}

Fistula entero-perineală este o complicaţie rară după amputaţia de rect pe cale abdomino-perineală.

Desfiinţarea spaţiului ,,mort“ pelvin şi disecţia corectă și completă a aderenţelor entero-pelvine atunci când ele sunt prezente ar reprezenta măsuri profilactice eficiente pentru prevenirea fistulei entero-perineale.

Din multitudinea de tehnici descrise în tratarea plăgii perineale după amputaţia de rect, propunem meșajul lojei rectale cu câmpuri moi, o metodă simplă și puţin utilizată în Occident.

Sunt necesare studii suplimentare pentru descifrarea relaţiei dintre aderenţele entero-perineale după amputaţia de rect și fistula entero-perineală, fapt ce ar conduce spre o codificare mai bună a tratamentului.

6. Eriksen $\mathrm{MH}$, Bulut $\mathrm{O}$. Chemotherapy-induced enterocutaneous fistula after perineal hernia repair using a biological mesh: a case report. International Medical Case Reports Journal. 2014;7:11-13.

7. Tomohiro K, Tsurita G, Yazawa K, Shinozaki M. Ileal strangulation by a secondary perineal hernia after laparoscopic abdominoperineal rectal resection: A case report. International Journal of Surgery Case Reports. 2017;33:107-111.

8. Yasukawa D, Aisu Y, Kimura Y, Takamatsu Y, Kitano T, Hori T. Which Therapeutic Option Is Optimal for Surgery - Related Perineal Hernia After Abdominoperineal Excision in Patients with Advanced Rectal Cancer? A Report of 3 Thought - Provoking Cases. Am J Case Rep. 2018;19:663-668.

9. Tang $L$, Zhao $P$, Kong $D$. The risk factors for benign small bowel obstruction following curative resection in patients with rectal cancer. World J Surg Oncol. 2018;16:212.

10. O'Reilly M, Mellotte G, Ryan B, O`Connor A. Gastrointestinal side effects of cancer treatments. Ther Adv Chronic Dis. 2020;11:1-7. 